\title{
Pediatric Pulmonology Year in Review 2015: Part 1
}

Richard Auten ${ }^{1}$, Jurgen Schwarze ${ }^{2}$, Clement Ren ${ }^{3}$, Stephanie Davis ${ }^{3}$, Terry L. Noah ${ }^{4}$

1. ConeHealth System, Greensboro NC, USA, richard.auten@conehealth.com

2. Dept. of Child Life and Health, The University of Edinburgh, Edinburgh, UK jurgen.schwarze@ed.ac.uk

3. Riley Children's Hospital, Indiana University School of Medicine, Dept. of Pediatrics, Indianapolis, IN USA sddavis3@iu.edu

4. Dept. of Pediatrics, University of North Carolina at Chapel Hill, Chapel Hill, NC, USA

terry noah@med.unc.edu

Correspondence: Terry L. Noah at terry noah@med.unc.edu; 450 Macnider Building, Campus Box 7217, University of North Carolina, Chapel Hill, NC 27599-7217. Facsimile (919) 966-6179, telephone (919) 966-1055.

Word count: 3411

This is the author's manuscript of the article published in final edited form as:

Auten, R., Schwarze, J., Ren, C., Davis, S., \& Noah, T. L. (2016). Pediatric Pulmonology year in review $2015:$ Part 1. Pediatric Pulmonology, 51(7), 733-739. https://doi.org/10.1002/ppul.23423 


\section{ABSTRACT}

Our journal covers a broad range of research and scholarly topics related to children's respiratory disorders. For updated perspectives on the rapidly expanding knowledge in our field, we will summarize the past year's publications in our major topic areas, as well as selected publications in these areas from the core clinical journal literature outside our own pages. The current review covers articles on neonatal lung disease, pulmonary physiology, and respiratory infection.

Word count: 71 


\section{Introduction}

Our journal covers a broad range of research and scholarly topics related to children's respiratory disorders. For updated perspectives on the rapidly expanding knowledge in our field, we will summarize selected publications from the past year in our major topic areas, as well as selected publications in these areas from the core clinical journal literature outside our own pages. The current review covers articles on neonatal lung disease, pulmonary physiology, and respiratory infection.

\section{Neonatal lung disease and bronchopulmonary dysplasia (BPD)}

Bronchopulmonary Dysplasia (BPD) and its Etiology

Premature birth has implications for long term health even without well-known complications like BPD, a well-established exacerbating factor for adverse pulmonary and neurodevelopmental outcomes. This continues to motivate the search for preventive strategies based on improved mechanistic insights, as well as more accurate descriptions of long-term pulmonary health effects, among others.

Clinical studies have made it clear that BPD is multifactorial and that multiple gene families contribute to increased BPD risk. BPD and prematurity are important predisposing factors for later susceptibility to sequelae of respiratory insults such as COPD. The developmental window(s) of vulnerability and the threshold magnitude of oxidative stress have been explored in a variety of animal model systems. Maduekwe et al. tested the concept that accumulated hyperoxia exposure during neonatal and juvenile lung development (time $x$ concentration) in mice would predict susceptibility to adult influenza-induced lung injury ${ }^{1}$. While a minimum FiO2 of 0.6 appeared to be required, it is not yet certain that early postnatal hyperoxia (postnatal days 4-8) is required for the phenotype of alveolar 
enlargement and aberrant elastin deposition in adult mice. Knaapi et al. ${ }^{2}$ report that overexpression of cathepsin $\mathrm{K}$, a protease implicated in inflammatory lung conditions such as BPD, in transgenic mice has some limited protective effects during neonatal hyperoxia exposure. Limiting the damage from positive pressure ventilation has been widely proposed and embraced, with a trend towards using volumetargeted SIMV. Musk et al. treated surfactant deficient premature lambs with synchronized intermittent mandatory ventilation (SIMV) or high frequency jet ventilation (HFJV) using a volume targeted approach $(7 \mathrm{~mL} / \mathrm{kg})$ for SIMV breaths in both treatment groups ${ }^{3}$. Although HFJV is designed to minimize airway pressure amplitude $(\Delta \mathrm{P})$ at the level of the alveoli, they reported no differences in gas exchange, pulmonary blood flow, or histologic evidence of lung injury between the two ventilation groups. The duration of the study was 180 minutes and the lambs were anesthetized with propafol and remifentanil, so it may be that differences between ventilation approaches would have emerged with longer duration and less sedation that would be typical in clinical applications. As in the clinical trials of mechanical ventilation approaches in ARDS, using an open-lung approach ${ }^{4}$ while avoiding overdistension may be the key to minimizing lung injury attributable to mechanical ventilation.

Host susceptibility factors based on genotype have been shown to be relevant for experimental BPD. Huusko and colleagues ${ }^{5}$ report for the Gen-BPD Study group that Kit ligand gene polymorphisms in humans are significantly associated with risk for BPD and importantly that elevations of Kit ligand protein in umbilical cord blood also confer elevated BPD risk. Because of the role of the Kit pathway in mast cell maturation and proliferation, elevated cord blood Kit ligand may be identifying proinflammatory conditions in utero, which are known to increase BPD risk.

As noted in the 2014 Year in Review, center effect is a profound determinant of BPD risk ${ }^{6}$ and there are numerous attempts to better characterize those at greatest risk early in their courses of treatment in order to intervene at the right time. A variety of so-called BPD risk scores have been developed to partly address this need. A single center study reported by Malkar et al. ${ }^{7}$ confirmed earlier 
reports that elevated respiratory severity at age 30 days, calculated as FiO2 x mean airway pressure, was predictive of mortality, which is unsurprising given that persistent need for mechanical ventilation at age 30 days would identify a very high risk group. As the authors pointed out, caution must be exercised when generalizing predictive scores obtained from a single center, particularly if the mortality or BPD risk in the center were skewed in some way.

Efforts to limit and optimize mechanical support have led to wider use of non-invasive positive pressure ventilation, albeit with limited high-quality data to guide its use. Li and colleagues ${ }^{8}$ report in a review and meta-analysis that NIPPV has not been shown to decrease the need for IPV, hastening to add that a sufficiently powered prospective study has yet to be conducted. A pilot study by Kugelman and colleagues ${ }^{9}$ takes a step in that direction by comparing the efficacy of nasal IPPV versus humidified high flow (1-5 LPM) nasal cannula (HFNC) to prevent intubation, and suggesting that HFNC may be as effective as IPPV Two limitations of the study are worth noting. First, the proportion of eligible patients actually enrolled was relatively small (76/293). Second, the choice of the flows delivered via HFNC were not systematically chosen by specified criteria. When patients do require endotracheal intubation, predicting successful extubation should limit further injury by limiting the need to re-recruit, and earlier extubation may improve outcomes ${ }^{10}$ Robles-Rubio et al. report an improved computational approach to respiratory inductance plethysmography that predicts extubation readiness in preterm newborns undergoing mechanical ventilation, observing that diminished variability of respiratory effort predicts failure ${ }^{11}$. It is unclear whether low variability represents immaturity of neural signaling, diaphragmatic responsiveness or some combination. The authors speculate that the combination of decreased air flow variability and increased rib cage movement variability may signal relatively ineffective respiratory behaviors. 
Prematurity: Pulmonary Sequelae

2015 was a particularly fertile year for publication of late pulmonary outcomes of prematurity in Pediatric Pulmonology. Thunqvist et al. ${ }^{12}$ report results from a longitudinal cohort of patients diagnosed at 36 weeks with moderate or severe BPD from a single center $(\mathrm{N}=55)$. Mechanics measured using the raised volume rapid thoracoabdominal compression (RVRTC) method showed similarly impaired volumes and compliance in both moderate and severe BPD at age 18 months relative to published age-matched standards. This is at odds with other studies that have shown greater impacts of disease severity on lung function, but the methodologic variations and validity of so-called normal standard values were discussed in detail by the authors. Ronkainen et al. ${ }^{13}$ used a similar approach comparing conventional spirometry and diffusion tests (DLCO) in 88 unsedated older children (10-11.5 yr) that were born before 32 weeks gestation with 88 similar age controls born at term. In line with the early childhood results, airflow limitations and diminished diffusion capacity were prevalent in preterm born children, and worse in those diagnosed with BPD compared with control subjects. These effects of prematurity on diffusion in older school age children differed from the results reported by Assaf et al. ${ }^{14}$ among sedated three year olds, which showed no effect of prematurity on DLCO. It must be noted that Assaf et al. studied healthy prematures only, at a gestational age of 31.7 weeks, meaning those unaffected by significant lung disease, thus a less vulnerable population.

Using spirometry, Gibson and colleagues measured pulmonary function in adults born as very low birth weight (VLBW) newborns in the late 1970 's to early 1980 's ${ }^{15}$. Airflow limitations were present in the VLBW group compared with those with birthweight $\geq 2.5 \mathrm{~kg}$, with a more pronounced decrement in those diagnosed with BPD. FEV1 in VLBW adults were more predictive of adult FEV1 than was the case with normal BW adults. Jiang et al. ${ }^{16}$ and Nève et al. ${ }^{17}$ contributed to addressing the need for more normative data by assessing pulmonary function in normal school-age subjects in their respective populations. The long-term clinical implications of the apparent deficits in lung function among adult 
survivors of premature birth, particularly those diagnosed with BPD, is not yet clear, but may be more severe than earlier appreciated, as reviewed by Ronkainen and colleagues ${ }^{13}$.

In a retrospective study, Cristea et al. reported clinical data on a cohort of infants with bronchopulmonary dysplasia (BPD) who were ventilator dependent; these investigators reported that this population had severe airway obstruction that remained unchanged over time ${ }^{18}$. These findings suggest that children with a history of severe BPD have substantial impairment in lung function that will likely persist into adulthood, placing them at increased risk for future chronic obstructive lung disease.

Lung Hypoplasia: Pulmonary Sequelae

Congenital diaphragmatic hernia represents a severe interruption of lung development in many cases. Although some may be asymptomatic, others may suffer fatal pulmonary hypoplasia. Survivors that required lengthy courses of mechanical ventilation may be at particularly high risk for abnormal long-term lung function. Healy and colleagues ${ }^{19}$ analyzed pulmonary function using RVRTC and whole body plethysmography in sedated $\mathrm{CDH}$ survivors during infancy ( 6 and 18 months) and found higher lung volumes and airway resistance in children with $\mathrm{CDH}$ complicated by pulmonary hypertension (PH). As the authors noted, this is consistent with prior reports of enlarged, simplified alveolar structure that accompanies disrupted pulmonary vascular development in $\mathrm{CDH}$-associated $\mathrm{PH}$. An important addition from this study is the observation of longitudinal evaluations, at least in a subset of subjects. In those for whom longitudinal data were obtained, the $\mathrm{PH}$-associated elevations in lung volumes persisted over time. Similar findings were noted by Panitch and colleagues ${ }^{20}$ who used similar methods. They reported that abnormalities persisted up to three years, with severity correlating with the magnitude of presumed hypoplasia (surrogates being the need for patch closure, duration of mechanical ventilation, need for ECMO). The 'catch up' potential for lung growth may be durably impaired in those with severe 
hypoplasia, often accompanied by persistent $\mathrm{PH}$, possibly reflecting a decreased repertoire of functional progenitor cells. The approach to ameliorating pulmonary hypoplasia in this disease has suffered from a dearth of mechanistic studies as outlined by a review of pre-clinical studies by Eastwood et al. ${ }^{21}$ The authors underscore the need for common outcome measures to enable proper comparisons among the therapeutic approaches.

\section{Pulmonary physiology}

Physiologic measurements play a critical role in the care and study of pediatric respiratory diseases. In order for physiologic data to be useful, proper acquisition is imperative and robust normal reference data must be available for comparison ${ }^{22}$. In a study of infants with cystic fibrosis, Anagostopoulou et al. ${ }^{23}$ reported that lung clearance index (LCI) values were falsely normal when obtained using multiple breath washout (MBW) measurements of sulfur hexafluoride (SF6) with commercial equipment. MBW calculates LCl by tracing the molar mass of SF6 as it falls from $100 \%$ to 2.5\%. The algorithm in commercial software utilizes end-inspiratory molar mass to define the initial $100 \%$ step in gas concentration. The investigators developed a refined algorithm that utilizes endexpiratory molar mass instead, resulting in more accurate $\mathrm{LCl}$ determination. In a study of flow dependence of specific airway resistance (sRaw) measurement using whole body plethysmography, Coutier et al. demonstrated that sRaw can be affected by the range of flows generated during the panting maneuver used to measure sRaw; narrowing this flow interval allowed better discrimination between asthma and normal children ${ }^{24}$.

Low and middle income countries have a heavy burden of infant respiratory disease, but resources and environment in these countries limit the ability to use conventional techniques for sedated infant lung function testing. Gray et al. conducted a pilot study in a semi-rural area of South 
Africa demonstrating the feasibility of obtaining tidal breathing recordings, exhaled nitric oxide, and multiple breath washout data in unsedated infants ${ }^{25}$. Obtaining data outside of the pulmonary function laboratory will allow for the collection of a larger and more diverse set of normal reference values, which increases the possibility of furthering our understanding of infant respiratory morbidity in third world countries.

Tidal breathing analysis is an especially appealing technique since it is non-invasive, does not require sedation and only minimal cooperation is needed to assess respiratory function ${ }^{26}$. In children following surgical repair of congenital diaphragmatic hernia, Laviola et al. used opto-electronic plethysmography to study thoraco-abdominal asynchrony and reported that diaphragmatic patching is associated with less asynchrony (or abnormality) compared to the primary suture approach to management ${ }^{27}$. Further study is required to determine if these findings are clinically relevant. Using respiratory inductance plethysmography (RIP) and measurement of the electrical activity of the diaphragm, Pham et al. demonstrated that high flow nasal cannula (HFNC) therapy in infants with bronchiolitis resulted in decreased work of breathing ${ }^{28}$. These findings support the use of HFNC in bronchiolitis, suggesting that RIP may provide an objective measure of the effect of HFNC on respiratory mechanics in this group of patients.

Preterm birth often leads to disrupted alveolar-capillary development ${ }^{29}$. Assaf et al. measured the diffusion capacity of the lung for carbon monoxide in healthy preterm (HP) infants and normal full term infants ${ }^{14}$. Surprisingly, DLCO was actually higher in HP infants compared to normal controls, and not associated with gestational age or duration of mechanical ventilation after adjusting for body length, sex, and race. However, a higher DLCO was associated with an increased number of pro-angiogenic circulating hematopoietic stem/progenitor cells and treatment with CPAP; thereby, identifying potential novel approaches for treatment and monitoring of preterm lung disease. Although most preterm 
infants receive respiratory support for only the first few weeks of life, some infants require long term mechanical ventilation, and little is known about their lung function.

Physiologic measurements also provide insight into the pathogenesis of different pediatric respiratory diseases. Mayer et al. prospectively performed modified spirometry in a cohort of patients with Duchenne muscular dystrophy and showed a rate of decline in forced vital capacity of approximately $5 \%$-predicted points per year between the ages of 5 to 24 years ${ }^{30}$. These data will be helpful in calculating sample sizes for future interventional trials. In 5 to 7 year old children previously hospitalized for bronchiolitis as infants, Lauhkonen et al. ${ }^{31}$ performed impulse oscillometry and found that persistent severe deficits were present in only a small minority of study subjects, suggesting that permanent lung function reduction associated with infantile bronchiolitis occurs in later childhood.

\section{Respiratory infection}

\section{Viral infections}

Viral lower respiratory tract infection (LRTI) in young children continues to be of intense research interest, not least because since it may predispose to asthma and decrements in lung function in later life. Studies of risk factors for severe LRTI found that increased levels of maternal folate in mid pregnancy are associated with a decreased risk of LRTI by 6 months of age, and correlate with cord blood IL-10 levels and inversely with cord blood eosinophil counts ${ }^{32}$, while bronchiolitis cases with blood eosinophilia had an increased length of hospital stay (LOS) and were more often mechanically ventilated (24.2\%) than those without eosinophilia $(7.2 \%)$ or without blood counts $(0.7 \%)^{33}$. Geographic clustering of LRTI cases identified air pollution and poor housing as community level risk factors for wheezing LRTI and viral LRTI, respectively, with higher socio-economic status reducing the risk ${ }^{34}$. Such community level risk factors may enable multifaceted interventions in communities to reduce childhood LRTI. 
RSV immune prophylaxis efficacy was studied retrospectively in several populations. In children with CF, routine RSV-prophylaxis significantly reduces RSV hospitalizations but has no impact on lung function and growth at 6 years of age ${ }^{35}$. In children with congenital heart disease, RSV prophylaxis significantly reduces all LRTI, LRTI-hospitalizations, and intensive care admissions ${ }^{36}$, but it does not seem to have an effect on hospitalizations in children with idiopathic lung disease, who have more frequent and longer RSV-hospitalizations than healthy children ${ }^{37}$.

Current 'hot topics' in bronchiolitis management include hypertonic saline (HS) inhalation, noninvasive ventilation (NIV), and $\mathrm{O}_{2}$-saturation targets. An RCT in 68 infants with hospitalized bronchiolitis compared 3\%HS to normal saline inhalation, both given with salbutamol, and did not find any difference in LOS or severity scores, but more cough and rhinorrhea after HS ${ }^{38}$. These findings do not support routine HS use in bronchiolitis, in keeping with 2 recent larger RCTs ${ }^{39,40}$ and a systematic review with meta-analysis ${ }^{41}$. Noninvasive ventilation (NIV) is often used in acute bronchiolitis. Assessment of diaphragmatic electrical activity and esophageal pressure changes showed that high flow nasal cannula therapy offloads the diaphragm and reduces work of breathing in bronchiolitis ${ }^{42}$. However, in a multicenter prospective audit NIV did not reduce the need for endotracheal intubation and ventilation in ex-premature infants (32-35 weeks of gestation) with bronchiolitis ${ }^{43}$, suggesting that further studies of NIV outcomes are required. Despite a recommended $90 \% \mathrm{O}_{2}$ saturation target for children with bronchiolitis (American Academy of Pediatrics), clinical practice varies considerably often targeting higher $\mathrm{O}_{2}$ saturations. A recent multicenter equivalence $\mathrm{RCT}$ in acute bronchiolitis demonstrates that the $90 \% \mathrm{O}_{2}$-saturation target is safe and that it may reduce the time until infants requiring oxygen become fit for discharge ${ }^{44}$.

It remains important to better understand the risk factors for long term sequelae of early childhood LRTI. In indigenous Australian infants, persisting symptoms at 3 weeks after acute bronchiolitis are associated with an increased risk for subsequent bronchiectasis, and previous 
hospitalization and household smoke are risk factors for respiratory readmissions ${ }^{45}$. Thus, optimized care following bronchiolitis and elimination of smoke exposure could improve long-term outcomes. The post-bronchiolitis risk of recurrent wheeze/asthma is modified by gender, with an increased risk in boys ${ }^{46}$, by excess weight at school age, but not by birth weight or excess weight in the first 1.5 years of life ${ }^{47}$, and by polymorphisms in the TLR4, CD14, and IL-13 genes ${ }^{48}$.

Community acquired pneumonia and parapneumonic effusion

While viral infection remains the most common cause of community acquired pneumonia (CAP) in U.S. children ${ }^{49}$, risk for bacterial infection and optimal use of antibiotics for severe CAP are still important issues worldwide. Second hand smoke (SHS) is a well-known risk factor. This was reinforced by a report from the Centers for Disease Control and Prevention's Etiology of Pneumonia in the Community study, in which children hospitalized with CAP from households with $\geq 2$ smokers had a longer length of stay and were more likely to require intensive care compared with children from households with no smokers ${ }^{50}$.

Recommendations to use narrower spectrum antibiotics for CAP have resulted in declining use of cephalosporins in some areas ${ }^{51}$. However, interesting data were reported by Breuer et al. ${ }^{52}$ who carried out a retrospective study of 337 children hospitalized with community acquired pneumonia (CAP) and compared outcomes between children treated with narrow spectrum antibiotics (penicillin, ampicillin, and amoxicillin) vs. broad spectrum antibiotics (ceftriaxone, cefuroxime, cefazolin). Children treated more broadly had statistically shorter admissions and fever duration. In a randomized placebo controlled trial, administration of azithromycin early in the course of illness significantly reduced severity of subsequent lower respiratory tract illness, in preschool children with histories of recurrent illness ${ }^{53}$; whether this is related to antimicrobial or anti-inflammatory effects is unclear. The Tucson 
Children's Study group reported evidence that early pneumonia may be among the most important early life risk factors for adult lung disease ${ }^{54}$.

Parapneumonic effusion (PPE) is an important and common complication of bacterial pneumonia, and its optimal management is still debated. Kontouli et al. ${ }^{55}$ reported on lung function and exercise capacity outcomes 2 years after PPE in a prospective study of 51 children, and found lower FVC \% predicted, FEV1 \% predicted, and FEV1/FVC in these children compared to healthy controls, but these changes were not felt to be clinically important. In another prospective study ${ }^{56}$, children $<16$ years hospitalized with CAP were followed prospectively and $25 \%$ developed PPE. Not surprisingly, evidence of bacterial infection was associated with increased risk for PPE. Interestingly, ibuprofen use prior to admission was also associated with increased PPE risk. Finally, Hanson and colleagues ${ }^{57}$ carried out an elegant prospective crossover trial in which children with PPE (mean age $3.5 \mathrm{yr}$ ) referred to interventional radiology were randomized to one of two regimens involving fibrinolysis with alteplase $0.1 \mathrm{mg} / \mathrm{kg}$ twice a day alternating with normal saline twice a day. Effusion volumes were followed with low dose CT. Alteplase resulted in reduction in PPE volumes compared to normal saline; and earlier administration of alteplase (days 1 and 3) also performed better than later (days 2 and 4).

\section{Conclusions}

In the past year, many articles have been published in Pediatric Pulmonology and elsewhere, to further advance our understanding of neonatal lung disease, pediatric pulmonary physiology, and respiratory infection in children. Subsequent articles in this Year in Review series will cover sleep and breathing disorders, cystic fibrosis, asthma, infection, diagnostic testing, rare lung diseases, and neuromuscular disorders. 


\section{REFERENCES}

1. Maduekwe ET, Buczynski BW, Yee M, Rangasamy T, Stevens TP, Lawrence BP, O'Reilly MA.

Cumulative neonatal oxygen exposure predicts response of adult mice infected with influenza A virus. Pediatr Pulmonol 2015; 50(3):222-230.

2. Knaapi J, Kiviranta R, Laine J, Kääpä P, Lukkarinen H. Cathepsin K overexpression modifies lung development in newborn mice. Pediatr Pulmonol 2015; 50(2):164-172.

3. Musk GC, Polglase GR, Bunnell JB, Nitsos I, Tingay D, Pillow JJ. A comparison of high-frequency jet ventilation and synchronised intermittent mandatory ventilation in preterm lambs. Pediatr Pulmonol 2015; 50(12):1286-1293.

4. Cinnella G, Grasso S, Raimondo P, D'Antini D, Mirabella L, Rauseo M, Dambrosio M. Physiological effects of the open lung approach in patients with early, mild, diffuse acute respiratory distress syndrome: An electrical impedance tomography study. Anesthesiology 2015 Nov;123(5):1113-21.

5. Huusko JM, Mahlman M, Karjalainen MK, Kaukola T, Haataja R, Marttila R, Toldi G, Szabó M, Kingsmore SF, Rämet M, et al., on behalf of Gen BPDSG. Polymorphisms of the gene encoding Kit ligand are associated with bronchopulmonary dysplasia. Pediatr Pulmonol 2015; 50(3):260-270.

6. Lapcharoensap W, Gage SC, Kan P, Profit J, Shaw GM, Gould JB, Stevenson DK, O'Brodovich H, Lee HC. Hospital variation and risk factors for bronchopulmonary dysplasia in a population-based cohort. JAMA Pediatr 2015 Feb;169(2):e143676.

7. Malkar MB, Gardner WP, Mandy GT, Stenger MR, Nelin LD, Shepherd EG, Welty SE. Respiratory severity score on day of life 30 is predictive of mortality and the length of mechanical ventilation in premature infants with protracted ventilation. Pediatr Pulmonol 2015; 50(4):363-369.

8. Li W, Long C, Zhangxue H, Jinning Z, Shifang T, Juan M, Renjun L, Yuan S. Nasal intermittent positive pressure ventilation versus nasal continuous positive airway pressure for preterm infants with respiratory distress syndrome: A meta-analysis and up-date. Pediatr Pulmonol 2015; 50(4):402-409. 
9. Kugelman A, Riskin A, Said W, Shoris I, Mor F, Bader D. A randomized pilot study comparing heated humidified high-flow nasal cannulae with NIPPV for RDS. Pediatr Pulmonol 2015; 50(6):576-583.

10. Robbins M, Trittmann J, Martin E, Reber KM, Nelin L, Shepherd E. Early extubation attempts reduce length of stay in extremely preterm infants even if re-intubation is necessary. J Neonatal Perinatal Med 2015;8(2):91-7.

11. Robles-Rubio CA, Kaczmarek J, Chawla S, Kovacs L, Brown KA, Kearney RE, Sant Anna GM. Automated analysis of respiratory behavior in extremely preterm infants and extubation readiness. Pediatr Pulmonol 2015; 50(5):479-486.

12. Thunqvist $P$, Gustafsson $P$, Norman $M$, Wickman $M$, Hallberg J. Lung function at 6 and 18 months after preterm birth in relation to severity of bronchopulmonary dysplasia. Pediatr Pulmonol 2015; 50(10):978-986

13. Ronkainen E, Dunder T, Peltoniemi O, Kaukola T, Marttila R, Hallman M. New BPD predicts lung function at school age: Follow-up study and meta-analysis. Pediatr Pulmonol 2015; 50(11):10901098.

14. Assaf SJ, Chang DV, Tiller CJ, Kisling JA, Case J, Mund JA, Slaven JE, Yu Z, Ahlfeld SK, Poindexter B, et al. Lung parenchymal development in premature infants without bronchopulmonary dysplasia. Pediatr Pulmonol 2015; 50(12):1313-1319.

15. Gibson A-M, Reddington C, McBride L, Callanan C, Robertson C, Doyle LW. Lung function in adult survivors of very low birth weight, with and without bronchopulmonary dysplasia. Pediatr Pulmonol 2015; 50(10):987-994.

16. Jiang M, Gao Y, Zhong N-S, Chen W-Q, Guan W-J, Zheng J-P. Spirometric reference values for healthy Han children aged 5-15 years in Guangzhou, southern China. Pediatr Pulmonol 2015; 50(10):10091016. 
17. Nève V, Edmé J-L, Baquet G, Matran R. Reference ranges for shape indices of the flow-volume loop of healthy children. Pediatr Pulmonol 2015; 50(10):1017-1024.

18. Cristea Al, Ackerman VL, Swigonski NL, Yu Z, Slaven JE, Davis SD. Physiologic findings in children previously ventilator dependent at home due to bronchopulmonary dysplasia. Pediatr Pulmonol $2015 ; 50(11): 1113-8$.

19. Healy F, Lin W, Feng R, Hanna BD, Hedrick H, Panitch HB. An association between pulmonary hypertension and impaired lung function in infants with congenital diaphragmatic hernia. Pediatr Pulmonol 2015; 50(7):672-682.

20. Panitch HB, Weiner DJ, Feng R, Perez MR, Healy F, McDonough JM, Rintoul N, Hedrick HL. Lung function over the first 3 years of life in children with congenital diaphragmatic hernia. Pediatr Pulmonol 2015; 50(9):896-907.

21. Eastwood MP, Russo FM, Toelen J, Deprest J. Medical interventions to reverse pulmonary hypoplasia in the animal model of congenital diaphragmatic hernia: A systematic review. Pediatr Pulmonol 2015; 50(8):820-838.

22. Stocks J, Modi N, Tepper R. Need for Healthy Control Subjects when Assessing Lung Function in Infants with Respiratory Disease. Am J Resp Crit Care Med. 2010; 182(11):1340-2.

23. Anagnostopoulou P, Yammine S, Schmidt A, Korten I, Kieninger E, Mack I, Trachsel D, Hafen G, Moeller A, Casaulta C, et al. False normal Lung Clearance Index in infants with cystic fibrosis due to software algorithms. Pediatr Pulmonol 2015; 50 (10):970-7.

24. Coutier L, Ioan I, Sadegh-Eghbali A, Bonabel C, Demoulin B, Le Tuan T, Marchal F, Schweitzer C, Varechova S. Flow dependence of specific airway resistance and diagnostic of asthma in children. Pediatr Pulmonol 2015; 50(11):1107-12.

25. Gray DM, Willemse L, Alberts A, Simpson S, Sly PD, Hall GL, Zar HJ. Lung function in African infants: A pilot study. Pediatr Pulmonol 2015; 50(1):49-54. 
26. Palmer JA, O Mayer. Tidal breathing analysis. NeoReviews. 2004; 5: e186-e93.

27. Laviola M, Zanini A, Priori R, Macchini F, Leva E, Torricelli M, Ceruti C, Aliverti A. Thoraco-abdominal asymmetry and asynchrony in congenital diaphragmatic hernia. Pediatr Pulmonol 2015; 50(9):91524.

28. Pham TMT, O'Malley L, Mayfield S, Martin S, Schibler A. The effect of high flow nasal cannula therapy on the work of breathing in infants with bronchiolitis. Pediatr Pulmonol 2015; 50(7):713-20.

29. Baraldi E, Filippone M. Chronic Lung Disease after Premature Birth. New Engl J Med. 2007; 357(19):1946-55.

30. Mayer OH, Finkel RS, Rummey C, Benton MJ, Glanzman AM, Flickinger J, Lindström BM, Meier T. Characterization of pulmonary function in Duchenne Muscular Dystrophy. Pediatr Pulmonol 2015; 50(5):487-94.

31. Lauhkonen E, Koponen P, Nuolivirta K, Paassilta M, Toikka J, Korppi M. Lung function by impulse oscillometry at age 5-7 years after bronchiolitis at age 0-6 months. Pediatr Pulmonol 2015; 50(4):389-95.

32. Kim JH, Jeong K-S, Ha E-H, Park H, Ha M, Hong Y-C, Bhang S-Y, Lee S-J, Lee K-Y, Lee S-H, et al. Relationship between prenatal and postnatal exposures to folate and risks of allergic and respiratory diseases in early childhood. Ped Pulmonol 2015; 50:155-63.

33. Shein SL, Li H, Gaston B. Blood eosinophilia is associated with unfavorable hospitalization outcomes in children with bronchiolitis. Ped Pulmonol 2016; 51: 77-83.

34. Beamer PI, Lothrop N, Lu Z, Ascher R, Ernst K, Stern DA, Billheimer D, Wright AL, Martinez FD. Spatial clusters of child lower respiratory illnesses associated with community-level risk factors. Ped Pulmonol 2015; published online: 5 Oct 2015, DOI: 10.1002/ppul.23332 
35. Groves HE, Jenkins L, Macfarlane M, Reid A, Lynn F, Shields MD. Efficacy and long-term outcomes of palivizumab prophylaxis to prevent respiratory syncytial virus infection in infants with cystic fibrosis in Northern Ireland. Ped Pulmonol 2016; published online: 25 Jan 2016, DOI: 10.1002/ppul.23376I.

36. Ozyurt A, Narin N, Baykan A, Argun M, Pamukcu O, Zararsiz G, Sunkak S, Uzum K. Efficacy of palivizumab prophylaxis among infants with congenital heart disease: A case control study. Ped Pulmonol 2015; 50:1025-32.

37. Drummond D, Thumerelle C, Reix P, Fayon M, Epaud R, Clement A, Mahloul M, Habouria D, Delacourt C, Hadchouel A. Ped Pulmonol 2015; published online: 4 Dec 2015, DOI: 10.1002/ppul.23354.

38. Flores P, Mendes AL, Neto AS. A randomized trial of nebulized 3\% hypertonic saline with salbutamol in the treatment of acute bronchiolitis in hospitalized infants. Ped Pulmonol 2015; published online: 3 Sept 2015, DOI: 10.1002/ppul.23306.

39. Silver AH, Esteban-Cruciani N, Azzarone G, Douglas LC, Lee DS, Liewehr S, Nazif JM, Agalliu I, Villegas S, Rhim HJH, et al. 3\% Hypertonic Saline Versus Normal Saline in Inpatient Bronchiolitis: A Randomized Controlled Trial. Pediatrics 2015; 136:1036-43.

40. Everard ML, Hind D, Ugonna K, Freeman J, Bradburn M, Cooper CL, Cross E, Maguire C, Cantrill H, Alexander J, et al.; SABRE Study Team. SABRE: a multicentre randomised control trial of nebulised hypertonic saline in infants hospitalised with acute bronchiolitis. Thorax 2014; 69:1105.

41. Maguire C, Hind D, Bradburn M, Everard ML. Hypertonic saline (HS) for acute bronchiolitis: Systematic review and meta-analysis. BMC Pulm Med 2015; 15:148.

42. Pham TM, O'Malley L, Mayfield S, Martin S, Schibler A. The effect of high flow nasal cannula therapy on the work of breathing in infants with bronchiolitis. Ped Pulmonol 2015; 50: 713-20

43. Tinnion R, Spencer J, Moss S, Fenton A. RSV: Immunoprophylaxis and non-invasive respiratory support in ex-preterms: A northern UK perspective. Ped Pulmonol 2015; 50: 1119-27 
44. Cunningham S, Rodriguez A, Adams T, Boyd KA, Butcher I, Enderby B, MacLean M, McCormick J, Paton JY, Wee F, et al.; Bronchiolitis of Infancy Discharge Study (BIDS) group. Oxygen saturation targets in infants with bronchiolitis (BIDS): a double-blind, randomised, equivalence trial. Lancet $2015 ; 386: 1041-8$

45. McCallum GB, Chatfield MD, Morris PS, Chang AB. Risk factors for adverse outcomes of Indigenous infants hospitalized with bronchiolitis. Ped Pulmonol 2015; published online: 17 Nov 2015 DOI: $10.1002 /$ ppul.23342.

46. Tse SM, Coull BA, Sordillo JE, Datta S, Gold DR. Gender- and age-specific risk factors for wheeze from birth through adolescence. Ped Pulmonol 2015; 50: 955-62.

47. Törmänen S, Lauhkonen E, Saari A, Koponen P, Korppi M, Nuolivirta K. Excess weight in preschool children with a history of severe bronchiolitis is associated with asthma. Ped Pulmonol 2015; 50: 424-30.

48. Jung Y-H, Seo J-H, Kim HY, Kwon J-W, Kim B-J, Kim H-B, Lee S-Y, Jang GC, Song DJ, Kim WK, et al. The relationship between asthma and bronchiolitis is modified by TLR4, CD14, and IL-13 polymorphisms Ped Pulmonol 2015; 50: 8-16

49. Jain S, Williams DJ, Arnold SR, Ampofo K, Bramley AM, Reed C, Stockmann C, Anderson EJ, Grijalva CG, Self WH, et al., for the CDC EPIC Study Team. Community-Acquired Pneumonia Requiring Hospitalization among U.S. Children. N Engl J Med 2015; 372:835-845.

50. Ahn A, Edwards KM, Grijalva CG, Self WH, Zhu Y, Chappell JD, Arnold SR, McCullers JA, Ampofo K, Pavia AT, et al. Secondhand Smoke Exposure and IIIness Severity among Children Hospitalized with Pneumonia. J Pediatr 2015; 167(4):869-874.

51. Williams DJ, Edwards KM, Self WH, Zhu Y, Ampofo K, Pavia AT, Hersh AL, Arnold SR, McCullers JA, Hicks LA, et al. Antibiotic Choice for Children Hospitalized With Pneumonia and Adherence to National Guidelines. Pediatrics 2015; 136(1):44-52. 
52. Breuer O, Blich O, Cohen-Cymberknoh M, Averbuch D, Kharasch S, Shoseyov D, Kerem E. Antibiotic treatment for children hospitalized with community-acquired pneumonia after oral therapy. Pediatr Pulmonol 2015; 50(5):495-502.

53. Bacharier LB, Guilbert TW, Mauger DT, Boehmer S, Beigelman A, Fitzpatrick AM, Jackson DJ, Baxi SN, Benson M, Burnham CA, et al.; National Heart, Lung, and Blood Institute's AsthmaNet. Early administration of azithromycin and prevention of severe lower respiratory tract illnesses in preschool children with a history of such illnesses: A randomized clinical trial. JAMA 2015 Nov 17; 314(19):2034-44.

54. Chan JY, Stern DA, Guerra S, Wright AL, Morgan WJ, Martinez FD. Pneumonia in childhood and impaired lung function in adults: a longitudinal study. Pediatrics. 2015; 135(4):607-16.

55. Kontouli K, Hatzuagorou E, Kyrvasilis F, Roilides E, Emporiadou M, Tsanakas J. Long-term outcome of parapneumonic effusions in children: Lung function and exercise tolerance. Pediatr Pulmonol 2015; 50(6):615-20.

56. Elemraid MA, Thomas MF, Blain AP, Rushton SP, Spencer DA, Gennery AR, Clark JE and On behalf of the North East of England Pediatric Respiratory Infection Study Group Newcastle upon Tyne, UK. Risk factors for the development of pleural empyema in children. Pediatr Pulmonol 2015; 50: 721726.

57. Hanson SJ, Havens PL, Simpson PM, Nugent ML, Wells RG. Intrapleural alteplase decreases parapneumonic effusion volume in children more than saline irrigation. Pediatr Pulmonol 2015; 50: $1328-1335$. 